\title{
NETWORKING TOURISM SMEs: E-COMMERCE AND E-MARKETING ISSUES IN REGIONAL AUSTRALIA
}

\author{
PATRICE BRAUN
}

School of Business, University of Ballarat, Ballarat, Vic 3353, Australia

\begin{abstract}
Networks, knowledge, and relationships have become crucial assets to business survival in the new economy. Research indicates that network building is a major new source of competitive advantage and an essential regional and indeed global management requirement. Because regional policies encourage interfirm alliances and the development of regional economic communities, the fostering of a culture of connectivity, networking, learning, and trust between regional Australian small and medium-size tourism enterprises (SMTEs) may offer a potential solution to the possible loss of competitive advantage for Australian tourism enterprises. It is suggested that SMTEs would benefit from increased information flow through regional networking and cooperative e-marketing campaigns to enhance market visibility, global positioning, and strategic leverage in the new economy.
\end{abstract}

$\begin{array}{lllll}\text { Network structures Networking } & \text { SMTEs e-Commerce e-Marketing } & \text { Regional } \\ \text { Collaboration Trust } & & & \end{array}$

Introduction

The knowledge economy is a strategic combination of many factors with new knowledge platforms and relationships underpinning competitive advantage. Enabled and driven by connectivity, the knowledge economy is challenging the fundamental bases of established government frameworks, conventional business practices, and traditional marketing disciplines. One can view the knowledge economy as a relational space in which the synergy of cooperative behavior (in the form of collective learning) facilitates actions in a dynamic marketplace laden with technological paradigms (Konstadakopulos, 2000). To achieve success in this techno-economic innovation paradigm requires new ways of thinking for all.

In order to compete in the knowledge economy, companies must be prepared to use technology-mediated channels, create internal and external value, formulate technology convergent strategies, and organize resources around knowledge and relationships (Rayport \& Jaworski, 2001). Governments must seek to define appropriate combinations of technologies, policy settings, and capacity building based on networked information technologies (APEC, 2001). On the marketing side, communica- 
tion and customization are among the new demands of the knowledge economy, whereby mass markets are a phenomenon of the past and interactive markets of one are the future (Wind \& Mahajan, 2001).

One consistent pattern in the new economic business process is the complex networks of interaction, whereby emphasis on collaboration between firms is placed as the key for new models of innovation (Marceau \& Dodgson, 1998). Research indicates that network building is not only a major new source of competitive advantage for any company, but a crucial asset to business survival and an essential global and, indeed, regional management requirement (Chisholm, 1998; Davis \& Meyer, 1998; MartinezFernandez, 1999; Milton-Smith, 1998; Porter, 1998). The very awareness of competitive international opportunities, and threats, has put regional interests, and hence the interests of small and medium-size enterprises (SMEs), back on the agenda (APEC, 2001; Boekholt, 1997). Regional innovation and growth theories in particular are focusing on the emergence of networks and the development of regional economic communities, whereby policy makers concerned with the performance of regional economies are seeking to foster a networked community culture (APEC, 2001; Martinez-Fernandez, 1999).

\section{Regional Innovation}

Regional development literature has proliferated in the last decade (Amin, 1999; Cooke \& Morgan, 1998; Diez, 2001; Henderson, 2000; Storper, 1997) with networking, learning, and regional development being portrayed as pivotal linkages for regional development and growth. In what Cooke (1996) initially termed a networked regional innovation architecture, a rapidly growing body of literature suggests that across continents regional innovation policy makers are planning and implementing network-based innovation policies. Examples of the network trend may be found internationally on the European Commission and the APEC action agendas to build flexible partnerships and regional networks (APEC, 2001). Stimulated by research pioneered in regional settings both in Europe and America, where evaluated regional economies demonstrated that learning and knowledge transfer through "networking" made the regions more dy- namic and maximized regional assets (Amin, 1999; Cooke, 1996), innovation programs are designed to stimulate learning, innovation, and regional development. The latter have also proven advantageous towards enhancement of business performance, collaboration, and networking (Cooke \& Wills, 1999; Henderson, 2000). Indeed, what was once endogenous regional development has evolved into an exogenous network or associational development paradigm (Amin \& Thrift, 1995; Cooke, 1996; Cooke \& Morgan, 1998; Diez, 2001; Morgan 1997; Nouwens \& Bouwman, 1995).

\section{Networks of Interaction}

Network formations may vary from existing cluster consortia to loosely coupled business systems, online networks, or emerging grass-roots economic community developments. No matter what the format, generally their aim, and the aim of regional policies, is to develop a more effective and prosperous business sector through interfirm cooperation, knowledge, and resource sharing (Chisholm, 1998; Diez, 2001). In the context of emerging technologies and related knowledge-economy business models of linking stakeholders in dynamic clusters (OECD, 1999), connectivity is revitalizing conventional reasons for clustering (e.g., creating critical mass), as it can help facilitate the knowledge-based infrastructure network imperative for today's competitive advantage (Porter, 1998).

It is believed that the prime driving force behind regional economic growth is no longer just the physical attributes of a region, but the social capital embedded within the region (Diez, 2001). Recognizing that economic growth is accomplished by designing regional policy initiatives that stimulate learning, regions are being turned into so-called learning regions in which socially a variety of agents and institutions take part in interactive learning cycles (Henderson, 2000; Morgan, 1997). Thus, by entering into an interactive learning process, regions can create competitive advantage. Although it may be argued that by developing infrastructure and by sharing new technologies, regions are able to reduce uncertainty for their industries and produce positive economic results, measuring the success factors of such linkages as networks, learning, and regional development is still in its infancy. Despite this popu- 
larly adopted regional development agenda, little empirical evidence is available as to its merit (Maskell, 1997).

Having examined the adoption rate of regional innovation systems, Bergman (2001) asserts that policies that work indirectly through the market structure of regional economies are preferable over direct intervention through innovation agencies. Focusing on the dynamic nature of the new economy, others (Maskell \& Malmberg, 1999; Storper, 1997) point out it is the capacity to learn and adaptation rate to change that defines the success of a region. Most important perhaps are the evaluation methods themselves, which are in need of reassessment. Evaluation models such as measuring adoption, economic impact, or monetary cost/benefit ratios are conspicuously traditional for this new generation of pluralist innovation policies and should be supplemented by innovative (e.g., interactive) and participatory evaluation processes (Diez, 2001).

\section{SME Networks}

Australian industry sectors that will most likely benefit from networking and related expansion into the e-commerce arena are expected to be those that offer products and services that are amenable to ecommerce. These sectors include information technology, tourism, entertainment, banking, and finance (NOIE, 2000a). The entertainment and tourism sectors are currently peaking 5\% higher than other Australian industry sectors. The tourism sector performance level may in part be attributed to the fact that large Australian tourism enterprises have embraced information and communications technologies such as global reservation systems (Applebee, Ritchie, Demoor, \& Cressy, 2002), and in part to the reduced cost of distribution Web-based travel services provide (Pappas, 2001). Whereas intermediaries such as travel agents were once indispensable, travelers can now enter their preferences-such as an airline, destination, desired travel times and dates-directly into a selected online booking system, which then processes the information and delivers a choice of options along with a secure transactions environment. Australian airline Qantas asserts that $70 \%$ of its airline ticket sales (which includes phone reservations and Web-based transactions) now take the form of e-tickets (NOIE, 2000b).
Albeit somewhat slow in the uptake and initially trailing business-to-consumer (B2C) and consumerto-consumer $(\mathrm{C} 2 \mathrm{C})$ systems, travel and leisure booking sites, retail, and business-to-business (B2B) ecommerce exchanges, often referred to as portals, are rapidly becoming the norm in Australia (Wilson, 2000). The popular media predicted that by 2001 more than $80 \%$ of large Australian organizations would support industry-specific B2B portals or some form of online clustering to accommodate B2B resources, extranets, customer and supplier integration as well as other interorganizational processes (Harpur, 2000). While such forecasts are not easily verified, the prevailing view is that network externalities such as Internet portals and new e-commerce technologies are necessary to transform business capabilities from a parochial to a global level (Davenport, Jarvenpaa, \& Beers, 1996; Goolsbee, 2000; Murray \& Trefts, 2000).

By facilitating B2C and B2B horizontal and vertical trading via automated e-commerce engines, the latest IT solutions are being touted as collaborative e-commerce solutions in which strategic industry alliances are key. Companies such as SAP promote global solutions through customized supply chain interfaces in which "customers, employees, suppliers and business partners work together in one virtual business environment as if they were all one company" (SAP, 2000, p. 16). Many such business applications revolve around supply chain partnering approaches and tend to focus on the needs of large enterprises rather than on the needs of the trading community (Forrester Research, 2001a).

Although technology providers are breaking out of the corporate straightjacket and appealing to SMEs to tap into networked business solutions (Hayes, 2001), such environments are not likely to be conducive to SME network adoption, or the fostering of collaborative networks, without addressing the needs of the trading community (Braun, 2001). B2B marketplaces tend to create value in generating lower prices for buyers and streamlining buyer and supply chain operations, neither of which are core objectives for nonaligned service industry SMEs such as Australian tourism operators. In addition, the B2C market the focus of today's e-commerce customer has shifted from early adopter firms to proven value and brand companies, which favorably positions many of the larger companies with 
an off-line established customer base and recognized branding (McKinsey, 2000). SME networks may never be in a position to challenge large firms as equals in the e-commerce marketplace, but even within regional competitive domains, issues such as network brand establishment and value for customers would need consideration.

Adoption of networked technologies by SMEs is directly related to the size and nature of SMEs and largely depends on their perception of affordability and opportunities for their business (OECD, 2000). In European studies on SME positioning in the new economy (Cooke \& Wills, 1999; Fariselli, Oughton, \& Picory, 1999), SME networking appears contingent on favorable economic climates (e.g., government-sponsored external networks), with such institutional factors directly affecting the relationships among different economic actors (Cooke \& Wills, 1999; Fariselli et al., 1999). In Britain commercial application service providers are facing an uphill battle with British SMEs showing no signs of interest in networked technologies (Forrester Research, 2001b).

Australian SMEs, which make up $96 \%$ of all Australian enterprises in the private nonagricultural sector (Australian Bureau of Statistics, 2000), are likely to display similar reticence towards adoption of networked solutions. New millennium research (NOIE, 2000b) indicates that SMEs still hesitate to invest their time and money in a rapidly changing economy. The study cites issues such as fear of isolation, competitor use of the Internet, alienating intermediaries, uncontrolled growth, lack of technology skills, and lack of a strategic sense of how to move forward as significant uptake barriers (NOIE, 2000b). The cost of access to telecommunications networks is relatively higher in rural areas, proving to be another limitation on the uptake of e-commerce in regional areas ("Regional Centres," 2000). These barriers tend to foster an element of inertia among Australian SMEs in adopting technology solutions. Australian SMEs also perceive innovation policies as pertaining to large firms and are hence suspicious of e-commerce regulations (NOIE, 2000b).

A 1999 national tourism online scoping study (CRC Tourism, 1999) found that large companies were adopting Internet technologies as a natural evolution of their business strategies with technology changes being facilitated by their existing infrastruc- ture and critical mass of personnel. In contrast, a dismal $4 \%$ of small and medium-size tourism enterprises (SMTEs) with an Internet presence were tourism and travel businesses. It was hence seen as imperative that SMTEs invest in skills and alliances to exploit new technologies and emerging markets to avoid potential loss of competitive advantage (CRC Tourism, 1999). A more recent study conducted in the Canberra region (Applebee et al., 2002) concluded that uptake had increased but that industry knowledge relating to the Internet still needed considerable expansion. Larger SMTEs used the Internet more than small SMTEs and nonusers had strong negative perceptions on the effectiveness and adoption of information and communication technologies (ICT). While studies on the adoption of ICT are important, too few attempts have been made to analyze the drivers leading to ICT changes in the tourism landscape (e.g., strategic, environmental, and marketing-based drivers), which would considerably broaden the research platform (Tremblay, 2002).

In the travel industry networks and new consortia seeking aggregate selling and sourcing capabilities are largely driven by the airline industry, which seeks extended global reach through strategically aligned partnerships and cost-saving synergies in services such as baggage handling, catering, engineering, and maintenance (Pappas, 2001). Large players with economies of scope are clearly in a position to dominate the market, but under the right circumstances the role of regional tourism and SMTEs can be significant (Buhalis, 2002; Prosser, Hunt, Braithwaite, Bonnett, \& Rosemann, 2000). In a decentralized industry climate with low entry barriers, Australian SMTEs can develop new service industry enterprises, create regional employment (Barry \& Robins, 2001), and attain a regional profile. SMTEs tend to operate in isolation and many are still uncommitted to industry initiatives such as accreditation, training, marketing, and visitor satisfaction (Tourism Victoria, 2001). Hence, value adding to their business through the uptake of technology and partnership building to create competitive advantage is not a priority. In addition, connectivity is not as prevalent in regional and remote Australia as infrastructure representatives would like us to believe. While new generations of connectivity based on satellite and radio wave technology have great potential for regional Australia, today's level of regional and rural con- 
nectivity is still a long way from broadband capacity and, for often geographically dispersed tourism operators, from reliably sharing resources and data.

Since joining an interfirm network will constitute an enormous conceptual leap into the future for many SMTE managers, more attention will need to be paid to inhibitive uptake factors such as lack of infrastructure, fear of competitors, and lack of strategic direction in the new economy (Crase, Lamb, \& Patullock, 2000). Considering that moving up the value curve in the knowledge economy is likely to comprise a steep learning curve for all (Earl, 2000; Ghoshal, Bartlett, \& Moran, 1999), e-commerce novices will need substantial encouragement and support to make them willing to take the e-business plunge. SMTE value creation should initially focus on e-business awareness among individual SMTEs to reduce isolation and maintain core market reach in a rapidly changing economy (Braun, 2001). SMTE capacity building will not only make e-markets more accessible, but also generate long-term support towards proactive economic intervention and partnership building (Forrester Research, 2001a).

\section{Partnership Building}

In the past, Australian SMEs have not been known for their collaborative approach to business (Australian Bureau of Industry Economics, 1995). However, a relatively recent study of 2500 Australian SMEs on their involvement in business networks noted a significant level of interest in networking or formulating networks in the future, indicating that networking is likely to become important in the business future of Australian SMEs (Dean, Holmes, \& Smith, 1997). Two types of business networks, formal and informal networks, were identified whereby formal networks constituted formal arrangements between companies to consolidate resources and informal networks were seen as loose arrangements facilitating information exchange. Service companies were notably more likely to be involved in formal and informal networking than manufacturing companies.

Lack of suitable partners, lack of time, and lack of financial assistance were cited as inhibiting factors for collaboration (Dean et al., 1997). Partnership building between firms is not solely contingent on sourcing funding or technology partners, but also on social contexts (Brown and Duguid 1998). A key social concern inhibiting cooperation is lack of trust (Australian Bureau of Industry Economics, 1995). Trust, or the lack thereof, is more likely to be an issue in networks than in one-on-one linkages, because the latter tend to be formulated as informal rather than formal agreements (Australian Bureau of Industry Economics, 1995).

There is a considerable body of literature on interfirm trust. SME fear of opportunistic behavior from competitors has alliance literature scholars (Gulati, 1995; Fukuyama, 1995) stress the importance of trust and personal interaction in interfirm alliances. Not all researchers believe that alliances necessarily have to be based on trust, as long as systemic mechanisms are in place that allow stakeholders to have confidence that alliance partners will exhibit cooperative rather than opportunistic behavior and not take competitive advantage of knowledge-based exchanges (Beamish, 1987; Das \& Teng, 1997). Others argue that trust can be built during the relational exchange (Gulati, 1995; Ring \& Van de Ven, 1992). Alternatively, the trust may be historical and already in existence between individuals of different firms with interaction taking place in an atmosphere of continued trust building between stakeholders (Konstadakopulos, 2000).

As noted earlier, strategic alliances in travel and tourism occur predominantly between big players (Pappas, 2001) (e.g., between airlines and hire car companies, between airlines and major credit card companies). In such alliances each business party has crucial roles to play, and must do so in an atmosphere of trust, unity, and collaboration. Airline alliances in Australia have predominantly been based on specific agreements that do not require the exchange of sensitive commercial information and have operated without strong commitment (Tourism Futures International, 1999). Partnership and trust building requires prolonged socialization and externalization to assure stakeholder sincerity (Nonaka \& Takeuchi, 1995). Anecdotal evidence of SMTEs in regional Victoria suggests that trust relationships among regional actors are parochial and built on long-term relationships. Steeped in sociocultural ties, the level of socialization and externalization appears to depend on individual SMTE positioning within the destination hub and its access to embedded information channels. 
With networking on the rise, the opportunity exists to cultivate a new ethos of connectivity, socialization, and trust between Australian SMTEs, but such a collaborative or network culture would need to be fostered. Informal processes such as attending seminars, local or regional association meetings, and online chats with other firm managers can establish a high level of interfirm relationship building (Leana, 1999). Incremental and more formal levels of collaboration can be introduced once SMTEs are receptive to transform relationships into dynamic cooperation between trusted SMTE partners within optimized information sharing environments. Such information partnership environments should have clearly defined collaboration benefits for participating SMTEs (e.g., saving time and resources yet retaining locus of control) and be linked to tangible rewards (e.g., enhanced market visibility), global positioning, and strategic leverage in the new economy through cooperative marketing incentives.

\section{SMTE Cooperative Marketing}

The digital marketplace not only brings rapid proliferation of new products and services, but also new ways of marketing. Information technology is slashing marketing cost, removing intermediaries, and redefining marketing relationships (Häubl \& Trifts, 2000; Rayport \& Jaworski, 2001). Like the aforementioned economic and policy practices, marketing in the cyber age requires dynamic and innovative strategies.

All markets are complex no matter what mechanisms are used by the buyer. Keeping up with rapidly changing marketing trends is a challenge for all firms but is particularly confronting for resourceand time-poor SMEs. Whereas SMEs were once able to intuitively grasp their market, emergent digital technologies are increasingly altering market segmentation and market predictability, making small firms more vulnerable to market changes (Gaulden \& Jackson, 2001).

For SMTEs the dominant functions of an online tourism business remain product promotion and information (Applebee et al., 2002; CRC for Sustainable Tourism, 1999). Because SMTEs are relatively new to the virtual world and have neither the expertise for continuous digital brand building nor the resources for compiling a complete picture of cus- tomer tastes and circumstances, they are in danger of being isolated and out of touch with changing market dynamics. To avail themselves of new data mining technologies and updated market research, SMTEs would do well to partake in cooperative online initiatives.

Cooperative marketing in the print and other conventional media has been in place in the State of Victoria since the inception of a Regional Cooperative Marketing Program (RCMP) in 1993. The program was developed by Tourism Victoria, the State's peak tourism body, as part of its strategic direction to develop integrated marketing campaigns for all its product regions and gain competitive advantage through regional cooperation. Over the years Victorian product regions have augmented their visibility by developing cross-media marketing campaigns, producing high standard collateral conform with state funding guidelines, and by harnessing regional industry dollars through brochure advertising sales. While the RCMP may be termed a success by the latter standards, program participation proved too costly for many SMTEs, which in some product regions resulted in limited industry participation and program dependency on local government contributions. Last year the RCMP framework was remodeled to augment industry participation by relaxing collateral production guidelines and related pricing structures and to stimulate cross-regional collaboration by modifying the funding distribution (Tourism Victoria, 2001).

As part of their cooperative campaign offering, product regions have been actively courting industry members to participate in new communications channels (e.g., offering e-commerce services via their respective product region Web sites). By including Web services in their cooperative campaigns, product regions hope to get more operators on board, obtain a bigger piece of the state cooperative funding pie, and increase market share. Because no RCMP regional Web directives are in place, product regions are implementing ad hoc Web services and participation schemes. In fact, regional e-commerce developments are in direct contrast to Tourism Victoria's own lagging objectives to build a comprehensive statewide site with listing, booking, and transaction services for Victorian tourism firms throughout the product regions. 
Because increased numbers of SMTEs are seeking a Web-based presence for information and marketing purposes (Applebee et al., 2002), regional programs are not only competing with their own state peak body for the SMTE marketing dollar but also with numerous independent commercial Web developers. Generally SMTEs are not in a position to afford listings on multiple Web sites, and anecdotal evidence in regional Victoria suggests that this smorgasbord of Web offerings has only added to technology uptake confusion for SMTEs with limited knowledge of e-commerce and small marketing budgets.

While independent Web developers can offer comprehensive Web services and a degree of tourism marketing, collaborative marketing is not a core objective. Cost versus prominence of listing on the vast Tourism Victoria site and participation requirements such as accreditation by 2003 may ultimately prove fatal for the state site. Having access to onestop-shop marketing services within their product region programs, which have established links to state and national tourism marketing bodies, could present better value for money for SMTEs. However, because SMTEs think with their hip pocket, regional marketing bodies responsible for product region marketing campaigns would need to aggressively market such benefits.

\section{Tourism Cooperatives}

With the rise of portals and Internet-based marketing, Victorian product regions are in an excellent position to apply upstream reach and product richness by extending their tourism marketing programs into Web-based cooperative marketing campaigns. Given that the regional tourism strategy (Tourism Victoria ,2001) and general marketing trend is towards relationship marketing, whereby firms adopt a mix of cooperative and competitive strategies with both clients and competitors (Young \& Wilkinson, 1997), joining a regional industry B2C portal can be advantageous for regional Victorian SMTEs in terms of pooling resources to conduct market research and accessing market reach incentives, yet effectively compete with rival SMTEs. When such an industry portal is designed for concurrent B2B functionality, SMTEs can value add to their business by accessing industry communication, support, and best practice content (Braun, 2001).
Most B2B portals still lack information exchange or interaction between stakeholders. However, there is a recent and rapid rise of interest in so-called enterprise portals (Harpur, 2000), which sport vertical B2B functions-including information taxonomy, content aggregation, publishing and industry linksas well horizontal personalization and virtual community functionalities. By satisfying both relational and transactional needs and fostering relationships and networks of interest within these e-market places (Armstrong \& Hagel, 1996), SMTE portals have the potential to engage SMTEs and become competitive online networks.

Earlier discussed network solutions appear ill suited for SMTE collaboration, and product region portals would need to provide suitable SMTE training programs and beneficial economic frameworks for SMTEs to be willing to participate. Cooperative marketing programs would either need to raise enough funds to provide these services or they might consider an alternative business structure (e.g., building a virtual cooperative).

Cooperatives are voluntary associations of individuals and small business owners formed to meet common economic, social, and cultural needs (International Cooperative Alliance, 1995); they merit another look in the digital economic light. Cooperatives date back to the 1840 s when British socialists set up the Rochdale Cooperative in response to changing economic times during the Industrial Revolution (James, 1999). Their crucial feature is the link between investment and return through participation and ownership.

Australian cooperatives, which are predominantly associated with primary industries, have been on the wane due to industry deregulations and reduced levels of support (James, 1999). Restructuring of traditional cooperative structures into shareholder-owned companies, which can attract outside investment and be listed on the Australian Stock Exchange, has, however, provided a welcome boost to ailing Australian cooperatives (Baker, 1998).

Nelson (1999) compares today's learning organizations to early cooperative models, which made a commitment to ongoing learning in order to compete in a difficult business market and achieve competitive advantage for their cooperative organization by being risk-takers, partnership builders, profitsharers, niche marketers, and investor-controlled 
business innovators (Nelson, 1999). He might have extended his comparison to industry networks, newgeneration cooperative structures similarly committed to resource sharing and knowledge innovation in an unpredictable economy. Electronic technologies are already being used to improve communication efficiency and effectiveness of cooperatives (Nelson, 1999). Product region marketing cooperatives in Victoria looking to enter the e-commerce arena would potentially benefit from formulating a cooperative or electronic business alliance for regional competitive advantage (Wilson, 2000).

How does a virtual tourism cooperative equitably capture value for regionally dispersed tourism operators with different income potential? There are many ways to structure a cooperative B2C and B2B portal (Kerrigan, Roegner, Swinford, \& Zawada, 2001) and create an environmental fit to suit segmentation, differentiation and position (Wilkinson \& Young, 1998). A traditional way is to link investment and return with participation and ownership. A regionally dispersed shareholder-owned structure might also wish to explore outside investment, advertising, and sponsorship structures. Another way is to base subscription on the number of hospitality services the participating SMTE runs and the number of users for each. Yet another approach is to tie cooperative membership fees to use of cooperative services (e.g., number of transactions, level of participation in cooperative marketing campaigns) or the size of the SMTE employee base using cooperative services (Kerrigan et al., 2001).

Defining the right portal model for regionally dispersed SMTEs is a difficult task. Given the reluctance of SMTEs to enter e-commerce and embrace networked solutions, there is much to be learned from the communication and trust-building experiences of stakeholders in existing cooperatives. Stakeholders need to develop a clear understanding of what they can gain from collaboration and what can keep them from being successful. By extending collaborative marketing to the Web, it is necessary to take stock of the benefits of collaborative marketing by exploring a common sequence of issues, questions, and challenges and by identifying the motivation for collective action, key activities, available resources, and stakeholder interests. Once individual and collective goal orientation is realized, participation in a regional industry cooperative is likely to perpetuate trust amongst regional SMTEs, which in turn will produce know-how and regional economic sustainability. Adding appropriate digital technology solutions to successful cooperative practices should result in a regional SMTE portal model that accommodates cooperative e-marketing objectives within a structure that allows SMTEs to save time, save resources, retain locus of control yet benefit from collaborative initiatives.

Because a cooperative portal has the potential to emulate all the benefits of a traditional cooperative and achieve competitive advantage through niche marketing, e-commerce procurement, SMTE information exchange, and knowledge management, ecooperatives may well emerge as a significant $21 \mathrm{st}$ century SMTE online model.

\section{Suggestions for Future Research}

This article has discussed how fostering of a culture of connectivity, networking, learning, and trust between regional Australian SMTEs may offer a potential solution to the possible loss of competitive advantage in the new economy. Because networking and cooperative relationships are considered prime determinants of commercial success, Australian SMTEs have the opportunity to both collaborate and compete by joining a regional marketing portal founded on cooperative principles such as sharing resources and exchanging industry knowledge.

Having drawn on the interdisciplinary fields of networking, trust, and cooperative structuring, it is suggested that overcoming potential loss of competitive advantage for SMTEs in the digital economy will require strategic SMTE community building with connectivity, collaboration, and trust as pivotal building components. As with any new model, there is the danger that significant additional factors may not have been taken into consideration. While this article demonstrates that in the new economy the focus has to remain on individual SMTE needs rather than on networked technologies, there is much scope for further cross-disciplinary research within both theoretical frameworks and practical applications. SMTE positioning in the global marketplace, public versus privately networked SMTE technologies, SMTE relationship marketing, and industry-based SMTE capacity building are all timely research directions for the knowledge economy. 


\section{Biographical Note}

Patrice Braun holds a Masters by Research degree from James Cook University of North Queensland in information delivery via the Internet for community use. Ms. Braun is an e-business lecturer and consultant and is currently undertaking doctoral research in regional connectivity and electronic commerce with a focus on the adoption of e-commerce and e-marketing technologies towards competitive advantage for small and mediumsize tourism enterprises in regional Australia.

\section{References}

Amin A. (1999). International Journal of Urban \& Regional Research, 23(2), 365-379.

Amin, A., \& Thrift, N. (1995). Globalization, institutions and regional development in Europe. Oxford: Oxford University.

APEC. (2001). Beijing Initiative on APEC Human Capacity Building, May 15-16, Beijing [Online]. http:// www.apec.org (retrieved 10/7/2001).

Applebee, A., Ritchie, B. W., Demoor, S., \& Cressy, A. (2002). Internet use in the ACT tourism industry: An investigation into adoption, education and training needs. Paper presented at the 12th International Research Conference of the Council for Australian University Tourism and Hospitality education (CAUTHE), Fremantle, Western Australia, February 6-9.

Armstrong, A., \& Hagel, J., III. (1996). The real value of online communities. Harvard Business Review, 74(3), 134141.

Australian Bureau of Industry Economics. (1995). Beyond the firm: An assessment of business linkages and networks in Australia. Research Reports, Productivity Commission [Online]. http://www.pc.gov.au/bie/research/ rr67/ index.html (retrieved 12/10/2001).

Australian Bureau of Statistics. (2000). Small business in Australia 1999 (Cat. No. 1321.0). Canberra: Author.

Baker, R. (1998). Cooperatives. Bulletin with Newsweek, 117(6136), 44-47.

Barry, T., \& Robins, P. (2001). Tourism trends and opportunities: What do they mean for regional Australia? Canberra: Bureau of Tourism Research.

Beamish, P. J. (1987). Joint ventures in LDCs: Partner selection and performance. Management International Review, 27, 23-37.

Bergman, E. M. (2001). Innovation system effects on technological adoption in a regional value chain. European Planning Studies, 9(5), 629-649.

Boekholt. P. (1997). Innovative networks in regional economies: Enhancing infrastructures for technology creation and transfer. In J. Mitra \& P. Formica (Eds.), Innovation and economic development, university-enterprise partnerships in action (pp. 119-137). Dublin/London: Oak Tree Press.

Braun, P. (2001). Regional tourism: Collaborative marketing goes digital. Sustainable Economic Growth for Regional Australia, 5th National Conference Proceedings,
Thuringowa, Qld, September 8-12.

Brown, J. S., \& Duguid, P. (1998). Organizing knowledge. California Management Review, 40(3), 90-111.

Buhalis, D. (2002). Conference reports. Tourism Management, 23, 427-428.

Cooke, P. (1996). The new wave of regional innovation networks: Analysis, characteristics and strategy. Small Business Economics, 8(2), 159-171.

Cooke, P., \& Morgan, K. (1998). The associated economy. Firms, regions and innovation. Oxford: Oxford University Press.

Cooke, P., \& Wills, D. (1999). Small firms, social capital and the enhancement of business performance through innovation programmes. Small Business Economics, 13(3), 219-234.

Chisholm, R. F. (1998). Developing network organizations, learning from practice and theory. Reading, MA: Addison Wesley Publishing Company.

Crase, L., Lamb, P., \& Patullock, E. (2000). Using electronic commerce to rejuvenate Australian regional communities: Competitive advantage or misplaced optimism? Paper at the Communications Research Forum, Canberra, October, La Trobe University, Albury/ Wodonga.

CRC Tourism. (1999). Meeting the challenge, national online tourism scoping study. IT program, CRC for Sustainable Tourism, produced for the Office of National Tourism, Department of Industry, Science and Resources, Canberra [Online]. http://www.isr.gov.au/ tourism (retrieved 09/10/ 2000).

Das, T. K., \& Teng, B. (1997). Sustaining strategic alliances: Options and guidelines. Journal of General Management, 22(4), 49-64.

Davis. S., \& Meyer, C. (1998). Blur, the speed of change in the connected economy. Oxford: Capstone Publishing.

Davenport, T., Jarvenpaa, S., \& Beers, M. (1996). Improving knowledge work processes. Sloan Management Review, 37(4), 53-66.

Dean, J., Holmes, S., \& Smith, S. (1997). Understanding business networks: Evidence from the manufacturing and service sectors in Australia. Journal of Small Business Management, 35(1), 78-85.

Diez, M. A. (2001). The evaluation of regional innovation and cluster policies: Towards a participatory approach. European Planning Studies, 9, 907-923.

Earl, J. M. (2000). Evolving the e-business. Business Strategy Review, 11(2), 33-38.

Fariselli, P., Oughton, C., \& Picory, C. (1999). Electronic commerce and the future for SMEs in a global marketplace: Networking and public policies. Small Business Economics, 12(3), 261-275.

Forrester Research. (2001a). B2B partnerships fall short. Press Release June 11, 2001. Received via email June 19, 2001.

Forrester Research. (2001b). Oracle faces uphill SME battle. Press Release June 28, 2001. Received via email 11/7/ 2001.

Fukuyama, F. (1995). Trust. New York: Free Press. 
Gaulden, C., \& Jackson, W. T. (2001). Fuzzy marketing: Implications for small business. Association for Small Business and Entrepreneurship Conference, New Orleans, February 27-March 3 [Online]. http://www.sbaer.uca.edu/ Research/2001/ASBE (retrieved 18/07/2001).

Goolsbee, A. (2000). Why the network effect is so striking. In T. Dickson (Ed.), Mastering strategy, the complete MBA companion in strategy (pp. 21-64). London: Pearson.

Goshal, S., Bartlett, C., \& Moran, P. (1999). A new manifesto for management. Sloan Management Review, 40(3), 9-21.

Gulati, R. (1995). Does familiarity breed trust? The implications of repeated ties for contractual choice in alliances. Academy of Management Journal, 38(1), 85-112.

Harpur, P. (2000, July 25). Enterprises are an open portal. The Australian, Cutting Edge, p. 2.

Häubl, G., \& Trifts, V. (2000). Consumer decision making in online shopping environments: The effects of interactive decision aids. Marketing Science, 19(1), 4-21.

Hayes, S. (2001, May 1). Oracle network for SMEs. The Australian, IT Section, p. 28.

Henderson, D. (2000). EU regional innovation strategies. Regional experimentalistm in practice? European Urban and Regional Studies, 7(4), 347-358.

International Cooperative Alliance. (1995). Statement on the co-operative identity, ICA News, 5/6 [Online]. http:// www.coop.org/ica/info/enprinciples.html (retrieved 21/ 08/2000).

James, D. (1999). Going forward, all for one and one for all. Business Review Weekly, 21(30), 86.

Kerrigan, R., Roegner, E. V., Swinford, D. D., \& Zawada, C. C. (2001). B2Basics. The McKinsey Quarterly, 1 [Online]. http://www.mckinseyquarterly.com/article_page.asp (retrieved 23/07/2001).

Konstadakopulos, D. (2000). Learning behaviour and cooperation of small high technology firms in the Asean region. ASEAN Economic Bulletin, 17(1), 48-62.

Leana, C. R. (1999). Organizational social capital and employment practices. Academy of Management Review, 24(3), 538-556.

Marceau, J., \& Dodgson, M. (1998). Systems of innovation. Innovation Summit Learned Group Reference Paper [Online]. http://www.isr.gov.au/industry/ summit/reference/learned_group/index.html (retrieved 26/09/2000).

Martinez-Fernandez, M. C. (1999). The network perspective in regional regeneration: An organic analysis of the Hunter Regional Network for Economic Development (Hunter Valley, NSW, Australia). Proceedings 23rd Conference of the Australia and New Zealand Regional Sciences Association International, Newcastle, September 19-22.

Maskell, P. (1997). Introduction. In Eskelinen (Ed.), Regional specialisation and local environment: Learning and competitiveness. Stockholm: NordREFO.

Maskell, P., \& Malmberg, A. (1999) Localised learning and industrial competitiveness. Cambridge Journal of Economics, 23(2), 167-185.

McKinsey. (2000, August). E-Commerce market likely to favour large companies. Asia Pulse.

Milton-Smith, J. (1998). The value of networking SMEs: The Asia-Pacific experience. In P. Formica \& D. Taylor (Eds.), Delivering innovation. Key lessons from the world-wide network of science and technology parks (pp. 225-248). Campanillas, Malaga: IASP.

Morgan, K. (1997). The learning region: Institutions, innovation and regional renewal. Regional Studies, 31(5), 491503.

Murray R., \& Trefts, D. (2000, Winter). The IT imperative in business transformation. Information Systems Management [Online]. www.ebiztechnet. com members/online/ 200702/alignment/alignment_1.html (retrieved 25/07/ 2000).

Nelson, W. J. (1999, July/August). Co-op member education needed in 21st century. Rural Cooperatives, 22-23.

NOIE. (2000a). T@king the plunge 2000: Sink or swim. Canberra: Commonwealth Department of Communications, Information Technology and the Arts Commonwealth of Australia.

NOIE. (2000b). E-Commerce beyond 2000. Canberra: Commonwealth Department of Communications, Information Technology and the Arts Commonwealth of Australia [Online]. http://www.noie.gov.au/publications/NOIE/ ecommerce_analysis/beyond2k_final.rtf )retrieved 26/9/ 2000).

Nonaka, I., \& Takeuchi, H. (1995). The knowledge-creating company: How Japanese companies create the dynamics of innovation. New York: Oxford University Press.

Nouwens, J., \& Bouwman, H. (1995). Living apart together in electronic commerce: The use of information and communication technology to create network organisations. Journal of Computer-Mediated Communication, 3(1) [Online]. http://www.ascusc.org/jcmc/vol1/issue3/ vol1no3.html (retrieved 5/3/2002).

OECD. (1999). Boosting innovation: The cluster approach. OECD Conference Proceedings, June 1999 [Online]. http://www. oecd.org (retrieved 20/06/2000).

OECD. (2000). A global marketplace for SMEs. Progress Report by the Industry Committee Working Party on SMEs, OECD online publication [Online]. http://www. oecd.org (retrieved 20/06/2000).

Pappas, G. (2001). The next chapter in business-to-consumer E-commerce: The impact of the Internet on the airline industry [Online]. www.bcg.com (retrieved 1/10/2001).

Porter, M. E. (1998). Clusters and competition. In On competition (pp. 197-287). Harvard Business Review Book, Harvard College, Harvard 1996.

Prosser, G., Hunt, S., Braithwaite, D., Bonnett, G., \& Rosemann, I. (2000). The significance of regional tourism. A preliminary report (Occasional Paper Number 2). Lismore, NSW: Centre for Regional Tourism Research, Southern Cross University.

Rayport, J. F., \& Jaworski, B. J. (2001). e-Commerce. Boston: McGraw-Hill.

Regional centres get a boost. (2000, August 15). The Australian, IT Section, p. 55.

Rheingold, H. (1993). The virtual community, homesteading 
on the electronic frontier. Reading, MA: Addison-Wesley Publishing.

Ring, P. S., \& Van de Ven, A. (1992). Structuring cooperative relationships between organizations. Strategic Management Journal, 13(7), 483-498.

SAP. (2000, July 25). Delivery the business Internet, special advertising promotion. The Australian, Special Advertising Promotion.

Storper, M. The regional world. London: Guilford Press.

Tourism Futures International. (1999). Strategic evaluation of airline alliances. Proceedings of Aviation 99 Conference, Sydney, July 12-13.

Tourism Victoria. (2002). Tourism Victoria's strategic plan 2002-2006 (in planning phase) [Online]. http:// www.tourismvic.gov.au. (retrieved 10/3/2002).

Tremblay, P. (2002). Tourism \& information technologies:
Mapping the sources of innovation. Proceedings of the 12th International Research Conference of the Council for Australian University Tourism and Hospitality education (CAUTHE), Fremantle, Western Australia, February 6-9.

Wilkinson, I., \& Young L. (1998). Thoughts about competing: Beyond relationship marketing (draft paper for Research Conference on Relationship Marketing), Emory University, Atlanta.

Wilson, E. (2000, July 18). Cooperation at hub of top e-commerce model. The Age, IT News2, p. 3.

Wind, J., \& Mahajan, V. (2001). Digital marketing. New York: John Wiley \& Sons.

Young, L. C., \& Wilkinson, I. (1997). The space between: Towards a typology of interfirm relations. Journal of Business to Business Marketing, 4, 53-97. 